See Article page 1181.

\section{Commentary: In the pursuit of perfect mitral valve repair: A stitch in time saves nine}

\author{
Andrea De Martino, MD, and Uberto Bortolotti, MD
}

In patients with mitral regurgitation (MR) due to degenerative disease, mitral valve repair (MVR) is commonly recognized as the gold standard treatment. In the early 1980s, the work by the Carpentier group contributed to popularizing MVR techniques, which were mostly based on extensive tissue resection, chordal translocation or manipulation, and rigid annuloplasty ring implantation. ${ }^{1}$ Such techniques became rapidly reproducible in most surgeons' hands, allowing successful repair of even extreme mitral valve pathologies without the need for prosthetic valve replacement.

In more recent years, MVR procedures have shifted toward avoidance of tissue resection, the so-called "respect nonresect" attitude, associated with extensive use of artificial neo-chordae. ${ }^{2}$ However, regardless of the technique used and the different surgical approaches, either traditional or minimally invasive, the main goal of MVR has always been to provide the patient with a durable repair and stable left ventricular function throughout an extended postoperative period. Indeed, recurrent MR due to imperfect repair is well known to be associated with reduced long-term survival. ${ }^{3}$

Generally, most reports analyzing the results of MVR in large patient series have considered actuarial freedom from $\geq 2+\mathrm{MR}$ as an adequate result even in the long term. ${ }^{2,4}$ Although the methods of quantifying the degree of MR may differ among groups, and technological progress from 2D to $3 \mathrm{D}$ echocardiography currently allows more precise evaluation of the mitral valve anatomy, assessment of MR severity may still be influenced by subjective evaluation and individual experience. The results reported by the Mount Sinai group in New York City, indicate that even a $1+$ residual MR must be considered as a less than optimal result after MVR. ${ }^{5}$ With this in mind, further repair

\footnotetext{
From the Section of Cardiac Surgery, University Hospital of Pisa, Pisa, Italy. Disclosures: Authors have nothing to disclose with regard to commercial support. Received for publication Nov 5, 2019; revisions received Nov 5, 2019; accepted for publication Nov 5, 2019; available ahead of print Nov 27, 2019.

Address for reprints: Uberto Bortolotti, MD, Sezione Autonoma di Cardiochirurgia Universitaria, Via Paradisa 2, 56124 Pisa, Italy (E-mail: uberto.bortolotti@med. unipi.it).

J Thorac Cardiovasc Surg 2020;160:1191-2

0022-5223/ $\$ 36.00$

Copyright (C) 2019 by The American Association for Thoracic Surgery

http://dx.doi.org/10.1016/j.jtcvs.2019.11.033
}

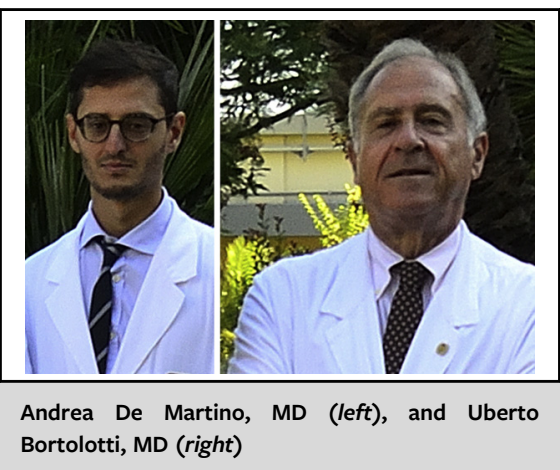

CENTRAL MESSAGE

Adequate repair is crucial in patients with degenerative mitral valve regurgitation. When the result is suboptimal, a second pump run, guided by an ad hoc algorithm, may provide a perfect result.

maneuvers were successfully attempted once intraoperative echocardiographic controls showed persistent MR and precisely demonstrated the cause of initial imperfect correction. This experience conveys some important messages: (1) in MVR, surgical experience is fundamental, but an extremely important prerequisite for success is also the expertise of the cardioanesthesiologist or whoever is in charge of the intraoperative echo; (2) the threshold for acceptance of the degree of any residual MR should be lowered to $<1+$, and this should be stressed in future guidelines; (3) the need for a second or even a third pump run should be considered not a harmful decision, but rather a means to avoid the consequences of an imperfect repair or implantation of a prosthetic valve, offering the patient a smoother postoperative period and better long-term outcomes without potential prosthesis-related complications; (4) the proposed algorithm resulting from the authors' experience is simple and clear and may be helpful in intraoperative decision making, so that the patient can leave the operative room with a repair as close as possible to the ideal one; and (5) the results of this aggressive attitude in treating residual MR indicate that outcomes are good, with low added risk at 5 years post-MVR. Is this the safest road to perfection? Hopefully yes; we are looking forward to longer-term follow-up data.

\footnotetext{
References

1. Carpentier A. Cardiac valve surgery: the "French correction." J Thorac Cardiovasc Surg. 1983;86:323-37.
} 
2. Shubert SA, Mehaffey JH, Charles EJ, Kron IL. Mitral valve repair: the French correction vs the American correction. Surg Clin North Am. 2017;97: 867-8.

3. Tomsic A, Hiemstra YL, van Hout FMA, van Brakel TJ, Versteegh NIM, Marsan NA, et al. Long-term results of mitral valve repair for severe mitral regurgitation in asymptomatic patients. J Cardiol. 2018;72:473-9.
4. Suri RM, Clavel MA, Shaff HV, Michelena HI, Huebner M, Nishimura RA, et al. Effect of recurrent mitral regurgitation following degenerative mitral valve repair: long-term analysis of competing outcomes. J Am Coll Cardiol. 2016;67:488-98.

5. El-Eshmawi A, Anyanwu A, Boateng P, Pawale A, Dimosthenis P, Himani B, et al. Second crossclamp to perfect degenerative mitral valve repair: decision-making algorithm, safety, and outcomes. J Thorac Cardiovasc Surg. 2020;160:1181-90.
See Article page 1181.

\section{Commentary: Mitral valve re-repair: Rejection of imperfection}

\author{
David D. Yuh, MD, FACS, FACC
}

In their retrospective review, El-Ashmawi and colleagues ${ }^{1}$ corroborate several previous studies that suggest that a second and perhaps even a third attempt at correcting less than moderate residual mitral regurgitation (MR) identified by intraoperative transesophageal echocardiography (TEE) after initial repair is generally safe when tempered with clinical judgment. $^{2-4}$ This persistence toward perfection to eliminate even mild mitral insufficiency appears further justified by evidence that achieving trace to no residual MR benefits long- and perhaps even short-term clinical outcomes. ${ }^{5,6}$

This study offers additional insight. First, it demonstrates that excellent mid-term outcomes can be achieved among patients requiring re-repair, with freedom from moderate or greater MR at 5 years. Second, a similar study by De Bonis and colleagues ${ }^{2}$ reported residual prolapse comprising almost one half of cases requiring re-repair, with nearly all remedied with an edge-to-edge "bail-out" technique. In sharp contrast, El-Ashmawi and colleagues found that residual MR was primarily suture-line related and employed more variegated re-repair techniques, using the edge-toedge technique in only 1 case. These differences illustrate the importance of a wide armamentarium of repair

From the Department of Surgery, Stamford Hospital, Stamford, Conn.

Disclosures: Author has nothing to disclose with regard to commercial support.

Received for publication Oct 13, 2019; revisions received Oct 13, 2019; accepted for publication Oct 15, 2019; available ahead of print Oct 25, 2019.

Address for reprints: David D. Yuh, MD, FACS, FACC, Department of Surgery, Stamford Hospital, One Hospital Plaza, P.O. Box 9317, Stamford, CT 06902 (E-mail: DYuh@stamhealth.org).

J Thorac Cardiovasc Surg 2020;160:1192-3

0022-5223/\$36.00

Copyright (c) 2019 by The American Association for Thoracic Surgery

http://dx.doi.org/10.1016/j.jtcvs.2019.10.064

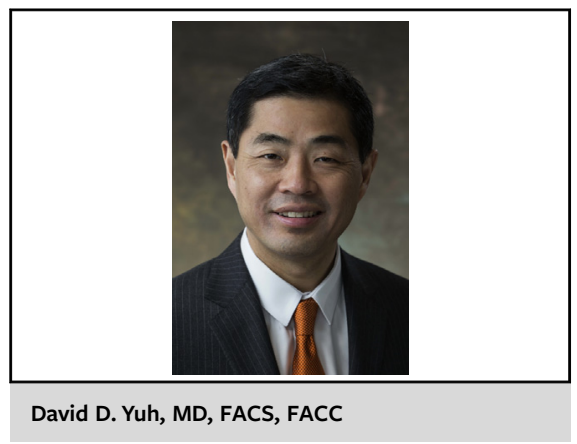

CENTRAL MESSAGE

Striving for structurally sound

mitral repairs, including re-repair,

should be standard practice to

maintain the "gold standard" of

surgical therapy against which

new devices must be compared.

techniques in facilitating effective and durable re-repair. Third, compared with previous investigations, this study demonstrated safe re-repair among patients requiring much longer initial aortic crossclamp times and cardiopulmonary bypass times (median 106 and 208.5 minutes, respectively) largely due to concomitant procedures $(85 \%)$ that now frequently accompany mitral repair (eg, tricuspid annuloplasty, radiofrequency ablation). It also appears that comparatively more challenging mitral repairs were undertaken in this cohort, with $55 \%$ of the repairs scored as "complex" with only $28 \%$ scored as "simple."

Promoting low thresholds for re-repair for even mild residual MR provokes consideration of re-repair for other "imperfections" noted on intraoperative TEE in the absence of residual MR that may predispose to late recurrent MR or other adverse hemodynamic consequence. For instance, Uchimuro and colleagues ${ }^{7}$ noted a trend toward 